\title{
大别山核部石鼓尖同构造花岗岩的变形与侵位: 对造山带构造体制转换的启示
}

\author{
邓新 ${ }^{(1)(3)}$ ，吴开涁 ${ }^{(1)}$ ，杨坤光 ${ }^{(1) *}$ \\ (1) 中国地质大学构造与油气资源教育部重点实验室, 武汉 430074; \\ (2) 中国地质大学地球科学学院, 武汉 430074; \\ (3) 武汉地质矿产研究所, 武汉 430205 \\ * 联系人, E-mail: yangkunguang@163.com
}

收稿日期: 2012-08-22; 接受日期: 2012-11-27; 网络版发表日期: 2013-08-08 国家自然科学基金(批准号: 40972137, 41172189)资助

摘要石鼓尖岩体位于大别山核部天堂寨地区, 为片麻理化石英二长岩. 岩体磁组构分析 显示, 磁面理主体倾向 SE, 倾角较大, $85 \%$ 采样点的倾角介于 $40^{\circ} \sim 90^{\circ}$ 之间, 与岩体的片麻理 产状一致. 岩体磁线理在东南部走向为 NWW-SEE 向, 在岩体中部和北部, 磁线理走向皆为 NE-SW 向. 在岩体中部, 磁线理向 SW 倾伏, 北部磁线理向 NE 倾伏, 磁线理倾角中等. 磁化 率各向异性度 $P$ 值介于 1.065 1.532 之间; 形态参数 $T$ 介于 $0.005 ~ 0.694$ 之间; 弗林图解 $(F-L$ 图解)显示 $K$ 值均小于 1 , 磁组构分析表明岩体是在 SE-NW 向挤压应力环境下侵位. 石英 C轴 组构分析表明, 岩体受到 SE-NW 向挤压应力, 变形温度在 $400 \sim 500{ }^{\circ} \mathrm{C}$ 之间. 显微构造显示岩 石具有接近固态的变形组构特征, 属同构造岩体变形组构. 结合岩体磁组构、显微构造和石英 $\mathrm{C}$ 轴组构, 指示石鼓尖岩体侵位冷凝成岩与区域 NE 向构造为同期, 属同构造侵入岩体. 石鼓 尖岩体 U-Pb 定年结果表明, 岩体锆石 U-Pb 年龄为 $(141 \pm 2.3) \mathrm{Ma}$, 代表岩体侵位结晶年龄. 综 合分析认为, 石鼓尖岩体侵位冷凝成岩时大别造山带仍然处于挤压环境, 造山带由挤压向伸 展转换的时间应该在 $141 \mathrm{Ma}$ 之后, 岩体侵位时大别造山带的构造演化已受控于滨太平洋构造 域. 而邻近的天堂寨等巨大岩基则是伸展环境的产物.

关键词

大别造山带

磁组构

石英 C 轴组构 构造体制转换
造山带花岗岩岩浆的形成、上升、侵位与变形和 区域构造变形关系密切, 花岗岩上升侵位过程记录 了造山带演化的重要动力学信息. 近年来许多研究 表明, 造山带花岗岩与区域构造变形的时空关系密 切, 分布在造山带中的花岗岩既可以形成在区域挤 压环境, 也可以形成在区域伸展环境下 ${ }^{[1 \sim 3]}$. 通过研
究花岗岩的变形和侵位, 能够揭示造山带构造演化 的重要动力学信息. 对花岗岩变形组构研究, 尤其是 对花岗岩的显微构造和磁组构特征进行研究, 可以 揭示花岗岩侵位的动力学机制, 为探讨花岗岩组构 与区域构造演化的关系、探讨花岗岩与造山带构造演 化关系研究提供了新思路 ${ }^{[47]}$.

中文引用格式: 邓新，吴开涁，杨坤光. 大别山核部石鼓尖同构造花岗岩的变形与侵位：对造山带构造体制转换的启示. 中国科学：地球科学, 2013, 43: $1381-1395$

英文引用格式: Deng X, Wu K B, Yang K G. Emplacement and deformation of Shigujian syntectonic granite in central part of the Dabie orogen: Implications for tectonic regime transformation. Science China: Earth Sciences, 2013, 56: 980-992, doi: 10.1007/s11430-013-4613-6 
大别造山带核部天堂寨地区分布有大面积的花 岗岩, 其同位素年龄主要集中在 143 120 Ma 之 间 ${ }^{[8 \sim 14]}$. 不同时间侵位的岩体其变形特征与岩石组构 明显不同. Wang 等 ${ }^{[12]}$ 和 $\mathrm{Xu}$ 等 ${ }^{[13,15,16]}$ 对这些花岗岩 的地球化学特征进行了大量的研究, 对其成因有比 较一致的认识, 但是对其变形特征、组构及其和造山 带构造体制的关系涉及较少. 对于大别造山带从挤 压动力体制向伸展动力体制转换的时间前人已有一 定的研究 ${ }^{[17 ~ 21]}$, 但具体转换的时间仍然存在争议. 本文通过对大别山天堂寨地区石鼓尖岩体的磁组构 测量, 显微构造观察和岩组测定, 发现石鼓尖岩体的 变形与围岩一致, 与 $\mathrm{NE}$ 向韧性剪切带相协调, 由此 确定石鼓尖岩体为与 $\mathrm{NE}$ 向㓞性剪切带同期的同构造 侵入岩, 并对大别造山带的构造演化和构造体制转 换进行更详细的讨论.

\section{1 区域地质背景及岩体宏观构造}

秦岭-大别-苏鲁造山带是华北板块与扬子板块 于三叠纪陆陆碰撞形成的造山带(图 1(a)). 其中大别 造山带西部与秦岭造山带相接, 东部通过欵庐断裂 带与苏鲁造山带相连, 南部边界为襄柇-广济断裂, 北部以合肥盆地与华北板块分开. 不同学者对大别 岩石构造单元的划分尚不一致 ${ }^{[19,22 ~ 26]}$. 本文参照 Zheng ${ }^{[26,27}$ 的研究结果, 将大别造山带从南到北划分 为以下几个岩石构造单元: 宿松绿片岩相-蓝片岩相 变质杂岩带、高压角闪岩相-石英榴辉岩相变质带、 超高压柯石英榴辉岩相变质带、北大别高温变质核杂 岩带和北淮阳低温低压浅变质带. 北大别高温变质 核杂岩带的北部边界为晓天-磨子潭断裂, 南界为五 河-水吼断裂, 主要为一套混合岩化的花岗质-英云闪 长质正片麻岩, 有大量燕山期岩浆岩侵入, 亦有少量 镁铁-超镁铁岩、榴辉岩及麻粒岩透镜体分布于片麻 岩及韧性剪切带中. 本文所研究的石鼓尖岩体出露 于北大别杂岩带的天堂寨地区(图 1(b)). 天堂寨地区 发育多期次侵入岩体, 岩体年龄在 143 120 Ma. 不 同期次岩体变形差异较大, 石鼓尖岩体等早期侵入 岩体变形明显(图 2(c), (d)), 可发育多期变形, 韧脆变 形共存; 天堂寨岩体等晚期侵入岩体变形不明显(图 2(a), (b)). 石鼓尖岩体是这些岩体中侵入较早的岩体, 变形较明显.

1) 湖北省地质矿产局. 张家咀幅 1:5 万地质图说明书. 1997
石鼓尖岩体呈 NNE 向延伸, 为边缘不规则的椭 圆形，与围岩大别杂岩呈侵入接触关系，出露面积约 为 $23 \mathrm{~km}^{2[15]}$ (图 1(c); $1: 5$ 万张家咀幅 $)^{1)}$. 岩体被 $\mathrm{NE}$ 和 NNE 向走滑型韧性剪切带(图 2(e), (f), (g), (h)) 围限, 岩体片麻状构造发育(图 2(c)), 片麻理走向皆为 NE-SW 向, 倾向 SE, 倾角在 $45^{\circ} \sim 70^{\circ}$ 之间. 岩体内部 发育捕虏体, 主要为大别杂岩, 在岩体内部和 NW 端 有后期岩体侵入. 岩体岩性为片麻状石英二长岩, 主 要矿物斜长石 $(35 \%)$ 、钾长石 $(25 \%)$ 、石英 $(10 \%)$ 和角 闪石 $(25 \%)$, 次要矿物黑云母 $(5 \%)$, 副矿物为磁铁矿、 锆石和磷灰石等.

\section{2 磁组构分析}

\section{1 样品的采集与测试}

在石鼓尖岩体中 33 个点采集磁组构样品, 采样 点均匀分布在岩体内部. 为了消除采样、测试过程中 出现的随机误差, 应用统计方法求取每个采样点的 平均值. 因此, 在每个采样点 $5 \mathrm{~m}^{2}$ 以内采集了 3 4 块 定向标本. 回到实验室用钻机在每个定向标本上钻 取 1 2 个定向岩芯, 保证每个采样点有 5 8 个定向岩 芯, 岩芯高 $22 \mathrm{~mm}$, 直径 $25 \mathrm{~mm}$. 磁组构的测试是在 中国地质大学(武汉)地球物理与空间信息学院磁学 实验室使用捷克 AGICO 的 Kappabridge 磁化率仪 (KLY-3S, 测试场强 $\pm 4 \times 10^{-4} \mathrm{~T}$, 测试频率 $875 \mathrm{~Hz}$, 检 出限 $2 \times 10^{-8} \mathrm{SI}$, 精度 $0.2 \%$ )完成.

\section{2 磁组构原理}

近年来, 越来越多的学者将岩石磁化率各向异 性运用于构造地质学的研究, 特别是对于在宏观尺 度难以观察到构造变形的花岗岩类, 运用岩石磁组 构研究其变形与侵位具有独特的优越性 ${ }^{[28 \sim 31]}$.

岩石磁化率各向异性的形成主要是因为定向应 力和温度作用, 起到决定性作用的是岩石形成时的 热动力学条件及其变化, 而与岩石成分以及其中所 含磁性矿物成分、数量的关系较小 ${ }^{[32]}$. 岩石的磁组构 特征通常以一个定向的椭球体表征，椭球体有三个 互相垂直的轴：最大磁化率主轴 $K_{\max }$, 中间磁化率主 轴 $K_{\text {int }}$ 和最小磁化率主轴 $K_{\text {min }}$, 这三个轴的相对大小 以及他们与水平面和地理北极的夹角构成了岩石磁 组构的基本要素. 通过前人的研究, 岩石磁化率椭球 

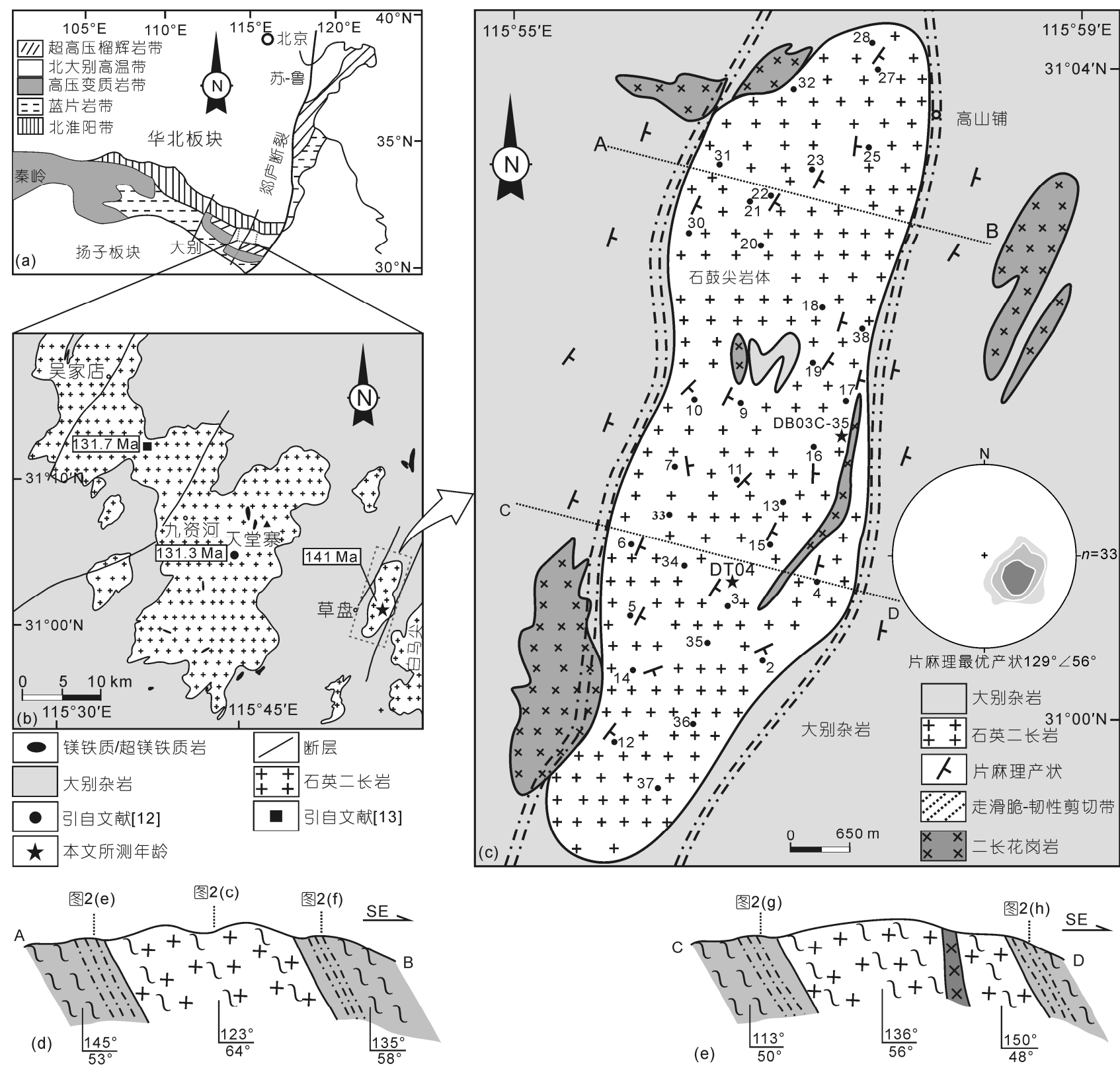

图 1 石鼓尖岩体区域构造简图

(a) 大别造山带岩石构造单元简图; (b) 大别造山带核部天堂寨地区花岗岩分布图; (c) 石鼓尖岩体地质图, 图上标明采样点位置和片麻理产 状, 右下角为岩体片麻理下半球赤平投影图, DT04 是本文 U-Pb 定年采样点, DB03C-35 是文献[15]中的锆石 U-Pb 定年点; (d) 图(c)中的 AB 剖面; (e) 图(c)中的 $\mathrm{CD}$ 剖面

体能在一定程度上反映岩石应变椭球体的特征, 磁 化率最小主轴平行于应变椭球最小主应变方向, 最 大主轴亦平行于应变椭球最大应变方向, 中间轴平 行于应变椭球体中间应变主轴 ${ }^{[32]}$. 而用于磁组构分 析的其他磁组构参数则由 $K_{\max }, K_{\mathrm{int}}$ 和 $K_{\mathrm{min}}$ 导出:

$K_{\mathrm{m}}$ (平均磁化率 $)=\left(K_{\mathrm{max}}+K_{\mathrm{int}}+K_{\mathrm{min}}\right) / 3$.

$$
P=K_{\max } / K_{\min }
$$

$F($ 磁面理 $)=K_{\mathrm{int}} / K_{\mathrm{min}}$.

$L($ 磁线理 $)=K_{\max } / K_{\text {int }}$.

$E$ (磁化率椭球的扁率 $)=\left(K_{\mathrm{int}}\right)^{2} /\left(K_{\max } \times K_{\min }\right), E>1$ 时为压扁椭球, $E<1$ 时为拉长椭球.

$T$ (磁化率椭球的形状因子) $=2 \ln \left(K_{2} / K_{3}\right) / \ln \left(K_{1} / K_{3}\right)$ 

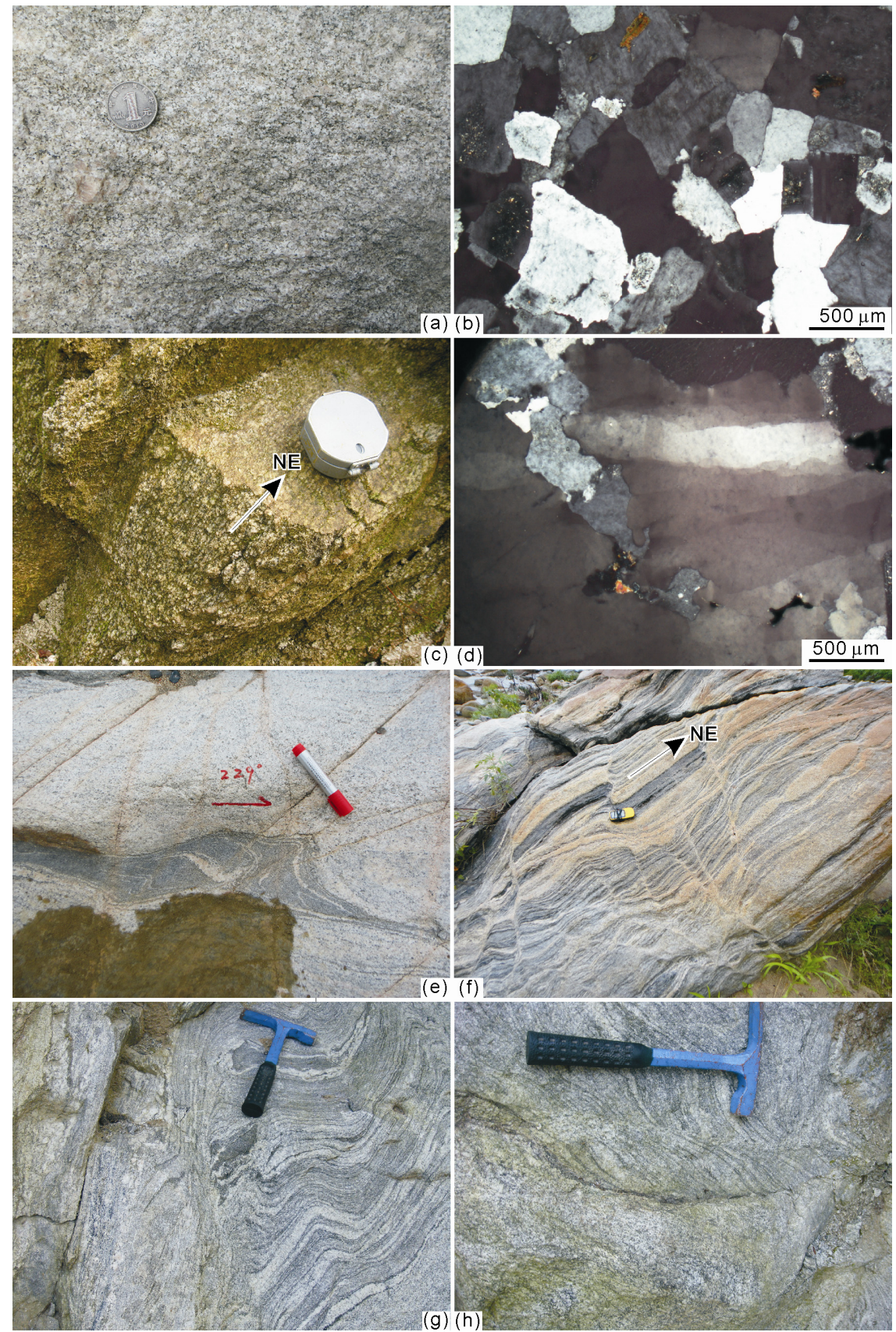

图 2 石鼓尖岩体宏观与显微照片

(a) 天堂寨未变形斑状二长花岗岩; (b) 天堂寨岩体在镜下呈现出岩浆结构, 显示岩体未发生变形; (c) 石鼓尖片理化石英二长岩, 片麻理走 向 NE, 倾向 SE; (d) 石鼓尖岩体在镜下呈现出石英带状消光及柱状亚颗粒, 岩体发生高温韧性变形; (e) 研究区 NE 向韧性剪切带中右行剪切 标志; (f) 研究区 NE 向㓞性剪切带中右行剪切标志; (g) 研究区 NE 向剪切带; (h) 研究区 NE 向剪切带

$-1^{[33,34]}, T=1$ 时, 磁面理和磁线理同等发育; $1>T>0$ 时, 磁面理比较发育; $T=0$ 时, 仅有磁面理发育; $0>$ $T>-1$ 时, 磁线理比磁面理发育; $T=-1$ 时, 仅有磁 线理发育.

\section{3 磁组构数据}

\subsection{1 平均磁化率及磁化率各向异性度}

石鼓尖岩体样品磁组构测量结果见表 1. 岩体体 
表 1 石鼓尖岩体磁组构参数 ${ }^{\text {a) }}$

\begin{tabular}{|c|c|c|c|c|c|c|c|c|c|c|c|c|}
\hline 采样点 & 品数 & $L$ & $F$ & $P$ & $T$ & $\left(10^{-6}\right.$ & $K_{1}$ & $K_{2}$ & $K_{3}$ & $\begin{array}{c}\text { 磁线理 } \\
\text { 产状 }\end{array}$ & $\begin{array}{c}\text { 磁面理 } \\
\text { 产状 }\end{array}$ & $\begin{array}{c}\text { 片麻理 } \\
\text { 产状 }\end{array}$ \\
\hline SG02 & 9 & 1.037 & 1 & 206 & 584 & 9860 & $63^{\circ} \angle 65^{\circ}$ & $186^{\circ} \angle 15^{\circ}$ & $282^{\circ} \angle 20^{\circ}$ & $63^{\circ} \angle 65^{\circ}$ & $102^{\circ} \angle 70^{\circ}$ & $155^{\circ} \angle 50^{\circ}$ \\
\hline SG03 & 13 & 029 & 14 & & 678 & 1040 & $124^{\circ} \angle 43^{\circ}$ & $323^{\circ} \angle 45^{\circ}$ & $223^{\circ} \angle 9^{\circ}$ & $124^{\circ} \angle 43^{\circ}$ & $43^{\circ} \angle 81^{\circ}$ & $123^{\circ} \angle 64^{\circ}$ \\
\hline SG04 & 5 & 36 & 218 & & 94 & 6 & $5^{\circ} \angle$ & - & & $5^{\circ} \angle$ & $3^{\circ} \angle$ & $4^{\circ} \angle 43^{\circ}$ \\
\hline SG05 & 11 & 1.028 & 104 & 143 & & & $216^{\circ} \angle$ & $3^{\circ} \angle 3^{\circ}$ & $3^{\circ}$ & $123^{\circ} \angle 47^{\circ}$ & $129^{\circ} \angle 47^{\circ}$ & $118^{\circ} \angle 61^{\circ}$ \\
\hline SG06 & 6 & 1.092 & 107 & .21 & 17 & 209 & $220^{\circ} \angle 8^{\circ}$ & $121^{\circ} \angle 47^{\circ}$ & $18^{\circ} \angle 42^{\circ}$ & $220^{\circ} \angle 8^{\circ}$ & $138^{\circ} \angle 48^{\circ}$ & $113^{\circ} \angle 46^{\circ}$ \\
\hline SG07 & 11 & 948 & 218 & 275 & & & $216^{\circ} \angle$ & & & $5^{\circ} \angle 46^{\circ}$ & $\angle$ & $32^{\circ} \angle 53^{\circ}$ \\
\hline SG09 & 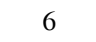 & 1.075 & 115 & 03 & & & $192^{\circ} \angle$ & & $2^{\circ} \angle 44^{\circ}$ & $192^{\circ} \angle 20^{\circ}$ & $122^{\circ} \angle 46^{\circ}$ & $117^{\circ} \angle 66^{\circ}$ \\
\hline SG10 & 5 & 1.09 & 1.127 & 1. & & 1 & $187^{\circ} \angle$ & $3^{\circ}$ & $8^{\circ} \angle 51^{\circ}$ & $83^{\circ} \angle 25^{\circ}$ & $138^{\circ} \angle 65^{\circ}$ & $135^{\circ} \angle 53^{\circ}$ \\
\hline SG11 & 10 & & 3 & & & & 1 & & & $\angle$ & $\angle$ & $134^{\circ} \angle 62^{\circ}$ \\
\hline SG13 & 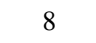 & 1.025 & 137 & 9 & 83 & 8160 & $\angle$ & & $356^{\circ} \angle 28^{\circ}$ & $152^{\circ} \angle 60^{\circ}$ & $176^{\circ} \angle 62^{\circ}$ & $132^{\circ} \angle 48^{\circ}$ \\
\hline SG14 & 10 & 1.026 & 1.12 & 1. & & & $208^{\circ} \angle$ & & & $\angle 79^{\circ}$ & ${ }^{\circ} \angle 81^{\circ}$ & $159^{\circ} \angle 67^{\circ}$ \\
\hline SG15 & 5 & 19 & 8 & & & & ${ }^{\circ} \angle$ & & & $\angle 72^{\circ}$ & $\angle 73$ & $117^{\circ} \angle 49^{\circ}$ \\
\hline SG16 & 14 & 1.063 & 1.20 & 1.298 & & & $176^{\circ} \angle$ & & & $176^{\circ} \angle 63^{\circ}$ & $126^{\circ} \angle 72^{\circ}$ & $92^{\circ} \angle 57^{\circ}$ \\
\hline SG17 & 8 & 1.108 & 1.2 & & & & $83^{\circ} \angle$ & 19 & $9^{\circ}$ & $\angle 41^{\circ}$ & $128^{\circ} \angle 51^{\circ}$ & $104^{\circ} \angle 56^{\circ}$ \\
\hline SG18 & 8 & 3 & 369 & 496 & & & $121^{\circ} \angle$ & & $54^{\circ}$ & ${ }^{\circ} \angle 36^{\circ}$ & $120^{\circ} \angle 36^{\circ}$ & $107^{\circ} \angle 40^{\circ}$ \\
\hline SG19 & 5 & 1 . & 1.23 & 1 & 4 & & $140^{\circ} \angle$ & 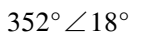 & & ${ }^{\circ} \angle 69^{\circ}$ & $78^{\circ} \angle 80^{\circ}$ & $123^{\circ} \angle 71^{\circ}$ \\
\hline SG20 & 烈 & 1.031 & 1.034 & 1.0 & & & $30^{\circ} \angle 5$ & 28 & $\angle 2^{\circ}$ & $30^{\circ} \angle 53^{\circ}$ & $117^{\circ} \angle 88^{\circ}$ & $126^{\circ} \angle 53^{\circ}$ \\
\hline SG21 & 10 & 1.029 & 1.14 & 35 & 6 & & $229^{\circ} \angle$ & $42^{\circ}$ & $31^{\circ}$ & $229^{\circ} \angle 33^{\circ}$ & $\angle 59^{\circ}$ & $131^{\circ} \angle 46^{\circ}$ \\
\hline SG22 & 10 & 1.019 & 1.10 & & & & $53^{\circ} / 83^{\circ}$ & & $311^{\circ} \angle 5^{\circ}$ & $53^{\circ} \angle 83^{\circ}$ & $131^{\circ} \angle 85^{\circ}$ & $122^{\circ} \angle 58^{\circ}$ \\
\hline SG23 & 8 & 1.171 & 1.299 & 1. & & & $77^{\circ} \angle 46^{\circ}$ & ${ }^{\circ} \angle 23^{\circ}$ & $301^{\circ} \angle 35^{\circ}$ & $77^{\circ} \angle 46^{\circ}$ & $121^{\circ} \angle 55^{\circ}$ & $117^{\circ} \angle 59^{\circ}$ \\
\hline SG25 & 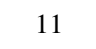 & 31 & 1.039 & 2 & 5 & & ${ }^{\circ} \angle 30^{\circ}$ & $\angle 47^{\circ}$ & $\circ \angle 28^{\circ}$ & $75^{\circ} \angle 30^{\circ}$ & $2^{\circ} \angle 62^{\circ}$ & $97^{\circ} \angle 41^{\circ}$ \\
\hline SG27 & 9 & 1.239 & 1.234 & 1 & & 87 & $77^{\circ} \angle 24^{\circ}$ & $170^{\circ} \angle 6^{\circ}$ & $274^{\circ} \angle 65^{\circ}$ & $77^{\circ} \angle 24^{\circ}$ & $94^{\circ} \angle 25^{\circ}$ & $125^{\circ} \angle 32^{\circ}$ \\
\hline SG28 & 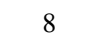 & & 1. & & & & $177^{\circ} \angle C$ & & & $177^{\circ} \angle 68^{\circ}$ & $122^{\circ} \angle 80^{\circ}$ & $136^{\circ} \angle 56^{\circ}$ \\
\hline SG30 & 11 & 1.096 & 1.2 & 1.385 & 0.424 & & ${ }^{\circ} \angle 12^{\circ}$ & ${ }^{\circ} \angle 11^{\circ}$ & $306^{\circ} \angle 74^{\circ}$ & $81^{\circ} \angle 12^{\circ}$ & $126^{\circ} \angle 16^{\circ}$ & $115^{\circ} \angle 62^{\circ}$ \\
\hline SG31 & 2 & 1.136 & 1.143 & 1.302 & 0.02 & & $25^{\circ} \angle 61^{\circ}$ & $180^{\circ} \angle 27^{\circ}$ & $274^{\circ} \angle 8^{\circ}$ & $25^{\circ} \angle 61^{\circ}$ & $94^{\circ} \angle 82^{\circ}$ & $134^{\circ} \angle 43^{\circ}$ \\
\hline SG32 & 9 & 1.044 & & & & & $\circ$ & & & ${ }^{\circ} \angle 48^{\circ}$ & ${ }^{\circ} \angle$ & $119^{\circ} \angle 56^{\circ}$ \\
\hline SG33 & 6 & 1.08 & 1.169 & 1.237 & .543 & 7960 & $206^{\circ} \angle 41^{\circ}$ & $60^{\circ} \angle 44^{\circ}$ & $312^{\circ} \angle 18^{\circ}$ & $206^{\circ} \angle 41^{\circ}$ & $132^{\circ} \angle 72^{\circ}$ & $128^{\circ} \angle 50^{\circ}$ \\
\hline SG34 & 8 & 1.057 & 1.239 & 1.3 & & & $233^{\circ} \angle 51^{\circ}$ & $110^{\circ} \angle 24^{\circ}$ & $337^{\circ} \angle 29^{\circ}$ & $233^{\circ} \angle 51^{\circ}$ & $157^{\circ} \angle 61^{\circ}$ & $124^{\circ} \angle 58^{\circ}$ \\
\hline & 6 & & 1.2 & & & & 11 & & & $\angle 32^{\circ}$ & 12 & $118^{\circ} \angle 52^{\circ}$ \\
\hline SG36 & 6 & 1.133 & 1.21 & & 0.226 & 136 & $81^{\circ} \angle 42^{\circ}$ & $207^{\circ} \angle 33^{\circ}$ & $320^{\circ} \angle 31^{\circ}$ & $81^{\circ} \angle 42^{\circ}$ & $140^{\circ} \angle 59^{\circ}$ & $131^{\circ} \angle 45^{\circ}$ \\
\hline SG37 & 5 & 1.159 & 1.112 & 1.2 & 0.109 & 298 & $73^{\circ} \angle 14^{\circ}$ & $176^{\circ} \angle 40^{\circ}$ & $328^{\circ} \angle 46^{\circ}$ & $73^{\circ} \angle 14^{\circ}$ & $148^{\circ} \angle 44^{\circ}$ & $127^{\circ} \angle 52^{\circ}$ \\
\hline SG38 & 8 & 1.04 & 1.302 & 1.565 & 0.65 & 178 & $130^{\circ} \angle 21^{\circ}$ & $222^{\circ} \angle 4^{\circ}$ & $321^{\circ} \angle 68^{\circ}$ & $130^{\circ} \angle 21^{\circ}$ & $141^{\circ} \angle 22^{\circ}$ & $129^{\circ} \angle 47^{\circ}$ \\
\hline
\end{tabular}

a) $K_{1}$ 为磁化率椭球最大主轴方向, $K_{2}$ 为磁化率椭球中间主轴方向, $K_{3}$ 为磁化率椭球最小主轴方向

积磁化率 $K_{\mathrm{m}}$ 值变化较大(图 3(a)), 从 $119 \times 10^{-6}$ 到 $9860 \times 10^{-6} \mathrm{SI}$, 主要集中在 $100 \times 10^{-6} \sim 500 \times 10^{-6} \mathrm{SI}$, 占 总测点的 76\%; $24 \%$ 测点在 $1000 \times 10^{-6} \sim 10000 \times 10^{-6} \mathrm{SI}$. 根据岩体平均磁化率的值可知, 大部分采样点 $\left(K_{\mathrm{m}}<\right.$ $\left.500 \times 10^{-6} \mathrm{SI}\right)$ 顺磁性矿物黑云母等对其贡献较大, 只 有少部分点 $\left(K_{\mathrm{m}}>500 \times 10^{-6} \mathrm{SI}\right)$ 铁磁性矿物如磁铁矿等 对其贡献大 ${ }^{[35,36]} . K_{\mathrm{m}}$ 在 $100 \times 10^{-6} \sim 500 \times 10^{-6} \mathrm{SI}$ 的点和 $K_{\mathrm{m}}$ 在 $1000 \times 10^{-6} \sim 10000 \times 10^{-6} \mathrm{SI}$ 的点散乱地分布在岩 体中, 没有明显的规律性, 表明磁性矿物在岩体中分 布不均匀.

岩体磁化率各向异性度 $P$ 值在 1.065 1.565 之间 (图 3(b)), 67\%测点 $P$ 大于 $1.2,27 \%$ 测点 $P$ 在 1.1 1.2 之间, 只有 $6 \%$ 测点 $P$ 小于 1.1 , 平均 1.27 , 总体上具
有较大的磁化率各向异性度值, 表明岩体磁组构的 形成受构造作用影响, 是构造成因磁组构 ${ }^{[37]}$. 根据 $K_{\mathrm{m}}-P$ 图解(图 3(e)), 随着 $K_{\mathrm{m}}$ 的增大, $P$ 并不线性增大, $P$ 值变化与 $K_{\mathrm{m}}$ 值无关. 因此, $P$ 值变化并不是磁性矿 物分布不均匀引起, 而是构造应力作用导致 $P$ 值变化.

\subsection{2 磁化率椭球体形态}

磁化率椭球体形态因子 $T$ 的分布和磁组构弗林 图解 $(F-L)$ 对岩石构造样式的判别具有一致性, 都能 够反映岩石的应变信息. 磁组构 $F-L$ 图解(图 3(c))显 示, 石鼓尖岩体所有样品都落在 $E>1$ 的区域, 说明岩 体变形以构造压扁为主, 磁面理比较发育. 磁组构的 $P-T$ 图解(图 3(d))显示, 石鼓尖岩体所有样品 $1>T>0$, 

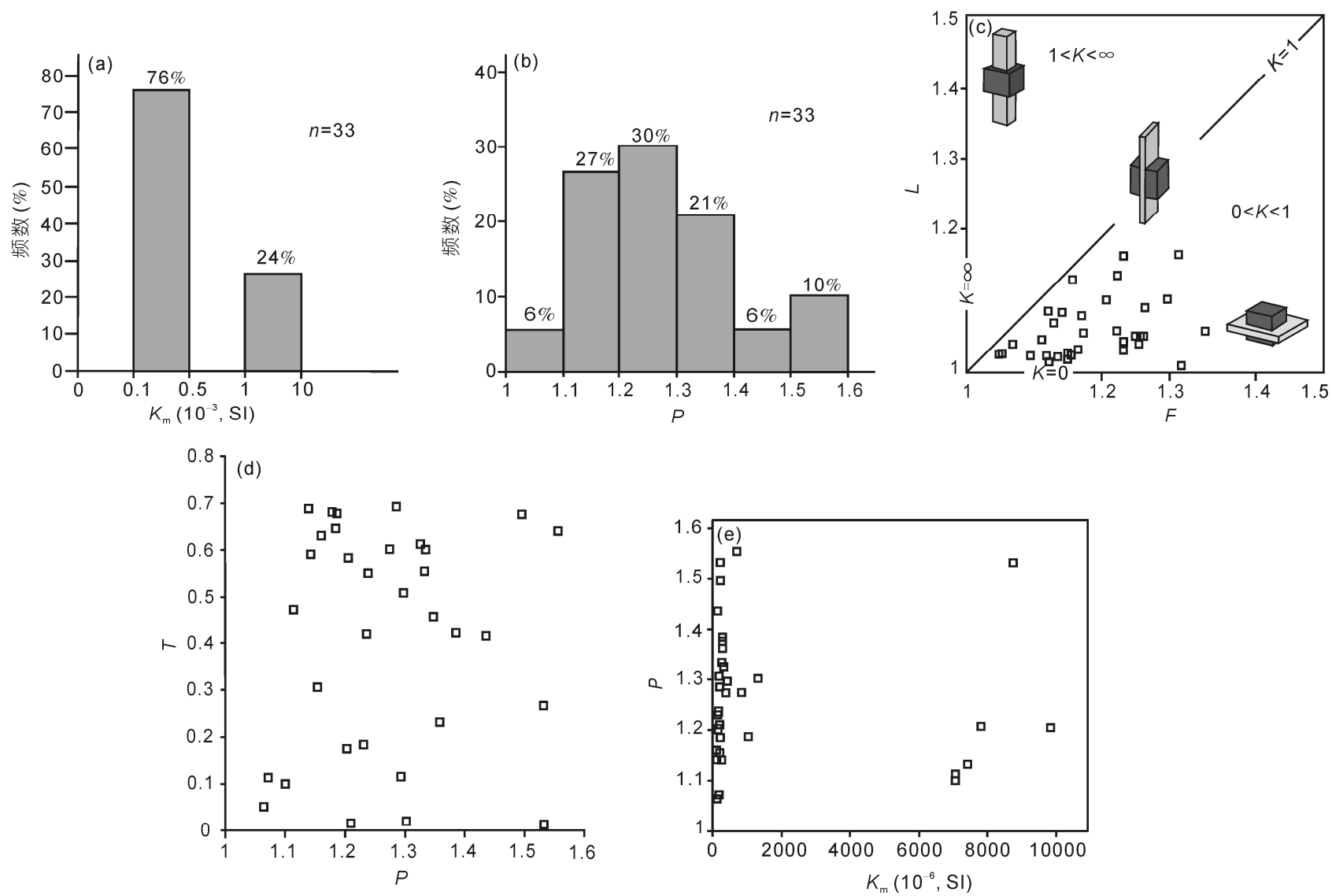

图 3 石鼓尖岩体磁组构参数图解

(a) 石鼓尖岩体体积磁化率 $K_{\mathrm{m}}$ 值频率图; (b) 岩体磁化率各向异性度 $P$ 值频率图; (c) 磁组构弗林 $(F-L)$ 图解, $0<K<1$ 为压扁区; (d) 磁组构 $P-T$ 图解; (e) 磁组构 $K_{\mathrm{m}}-P$ 图解

在 0.005 0.694 之间, 则岩体磁面理发育, 磁化率椭 球体以压扁为主, 岩体构造变形为挤压变形.

\subsection{3 磁面理}

石鼓尖岩体磁面理(图 4(a))走向总体为 NE-SW 向, 倾向 SE，与岩体宏观片麻理走向和倾向基本一 致. 磁面理倾角都较大, $70 \%$ 的测点倾角在 $50^{\circ} \sim 90^{\circ}$ 之 间, $15 \%$ 测点倾角在 $40^{\circ} \sim 50^{\circ}$ 之间, 只有 $15 \%$ 的点倾角 在 $10^{\circ} \sim 40^{\circ}$ 之间.

\subsection{4 磁线理}

石鼓尖岩体的磁线理分布具有明显的规律性(图 4(b)). 在岩体东南部, 磁线理走向为 NWW-SEE 向; 在岩体中部和北部, 磁线理走向皆为 NE-SW 向, 有 部分点不协调. 但在岩体中部, 磁线理向 SW 倾伏, 北部磁线理向 NE 倾伏. 磁线理倾角中等, $36 \%$ 测点
倾角在 $10^{\circ} \sim 40^{\circ}$ 之间, $48 \%$ 测点倾角在 $40^{\circ} \sim 70^{\circ}$ 之间, $16 \%$ 测点倾角在 $70^{\circ} \sim 90^{\circ}$ 之间. 石鼓尖岩体磁线理特 征表明, 岩体的流动磁组构虽然受构造变形组构叠 加，但能够大体反映岩浆流动信息，在岩体侵位过程 中，岩浆从岩体中部分别向 SW 和 NE 方向流动以扩 展空间，岩浆补给通道在岩体中部.

\section{3 显微构造与石英 $\mathbf{C}$ 轴组构}

\section{1 显微构造}

花岗岩类侵入体的变形可以发生在岩浆阶段, 也可以发生在固态条件. 每个状态下的变形有其特 别的组构. 从石鼓尖岩体内部及边缘 33 个采样点采 集岩石标本磨制薄片, 在显微镜下进行观察. 从薄片 中观察到以下组构: (1) 在部分采样点黑云母晶体沿 着 NE-SW 向定向分布, 晶体呈自形到半自形(图 5(a)); 


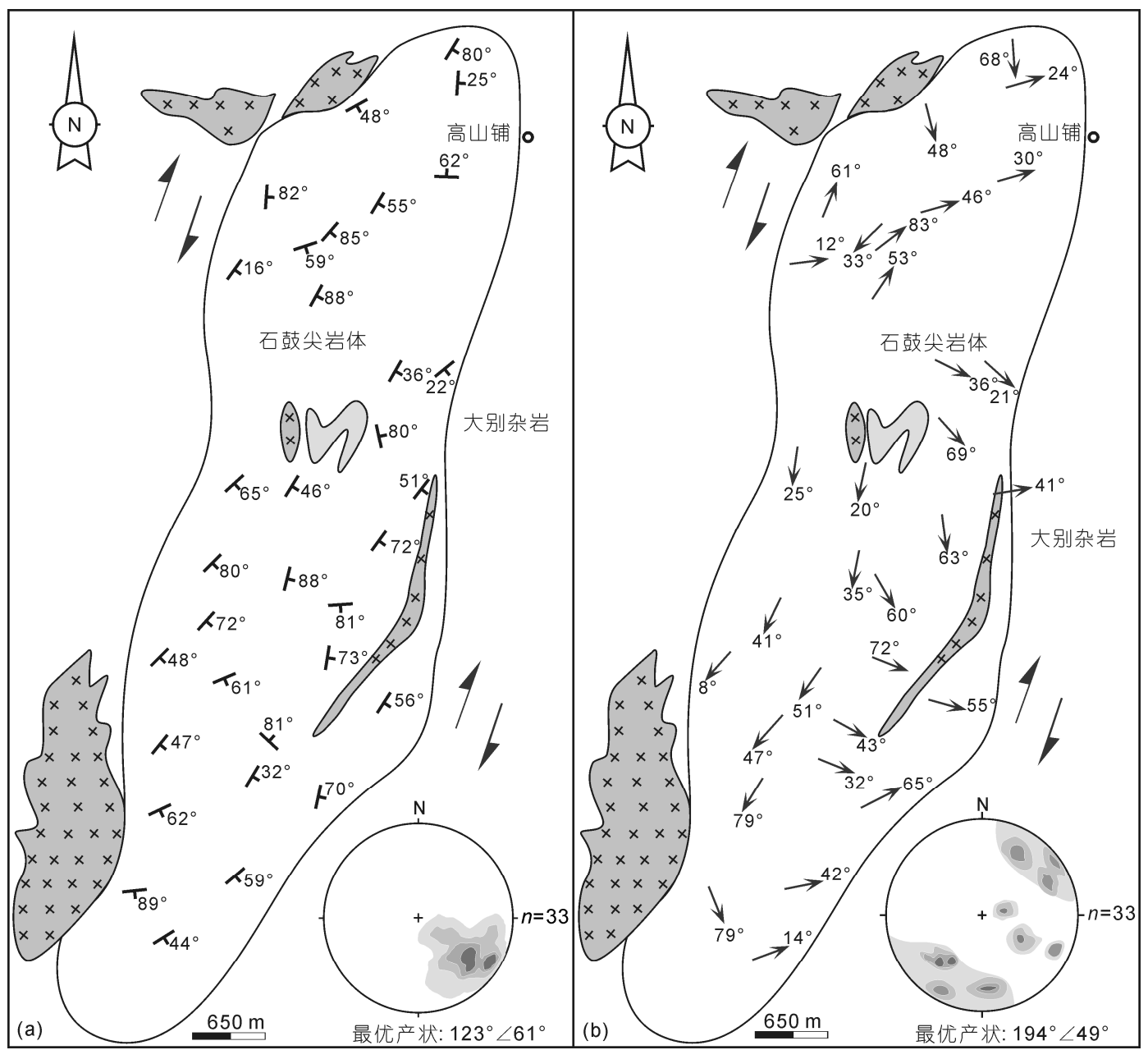

图 4 石鼓尖岩体磁面理分布及产状(a)和磁线理分布及产状(b)

钾长石自形-半自形晶体长轴规律地呈 NE-SW 向展 布(图 5(b)), 造成钾长石沿 NE-SW 向的定向排列. 自 形-半自形矿物晶体沿 NE-SW 向定向排列反映岩体 在冷凝结晶过程中受到 NW-SE 向挤压应力作用. (2) 岩体中蠕英结构普遍发育 (图 5(c)), 蠕英结构的出现 与压应力有关, 属于典型的高温变形组构 ${ }^{[38]}$. (3) 石 英晶体棋盘状结构发育, 亚晶粒边界平行于晶体界 面(图 5(d)), 反映岩体在高温接近固结成岩情况下发 生变形 ${ }^{[39]}$. (4) 钾长石晶体发育应力条纹(图 5(e)). 在 应力作用下, 钾长石的钠质出溶或者析出形成应力 条纹. (5) 石英条带状消光及柱状亚颗粒(图 5(f)) 普遍 出现在薄片中, 这种构造的出现与应力有关, 应力导 致晶格位错运动形成规则的位错壁, 由位错壁分割 成不同的消光区. 所有显微组构都表明石鼓尖岩体在
高温接近固结成岩的情况下发生构造变形. 众所周知, 钾长石发生变形及重结晶的温度大于 $500^{\circ} \mathrm{C}^{[4,40]}$, 石鼓 尖岩体出现钾长石的变形及重结晶表明岩体变形温 度大于 $500^{\circ} \mathrm{C}$. 石英棋盘状结构的发育同样证明岩体 变形温度大于 $500^{\circ} \mathrm{C}^{[41]}$.

\section{2 石英 $\mathbf{C}$ 轴组构分析}

在石鼓尖岩体中采集定向标本切制最大变形面 (XZ 面)薄片, 在普通费氏台上进行石英 $\mathrm{C}$ 轴组构分 析, 每个薄片测量 176 200 个颗粒, 利用 StereoNett2.46 软件进行等面积网下半球投影, 做成岩组图 (图 6). 石鼓尖岩体石英 $\mathrm{C}$ 轴组构图的对称形式为斜 方对称, 在部分样品中叠加单斜对称, 主要发育极密 和交叉环带两种优选方位. 最大极密值集中在 

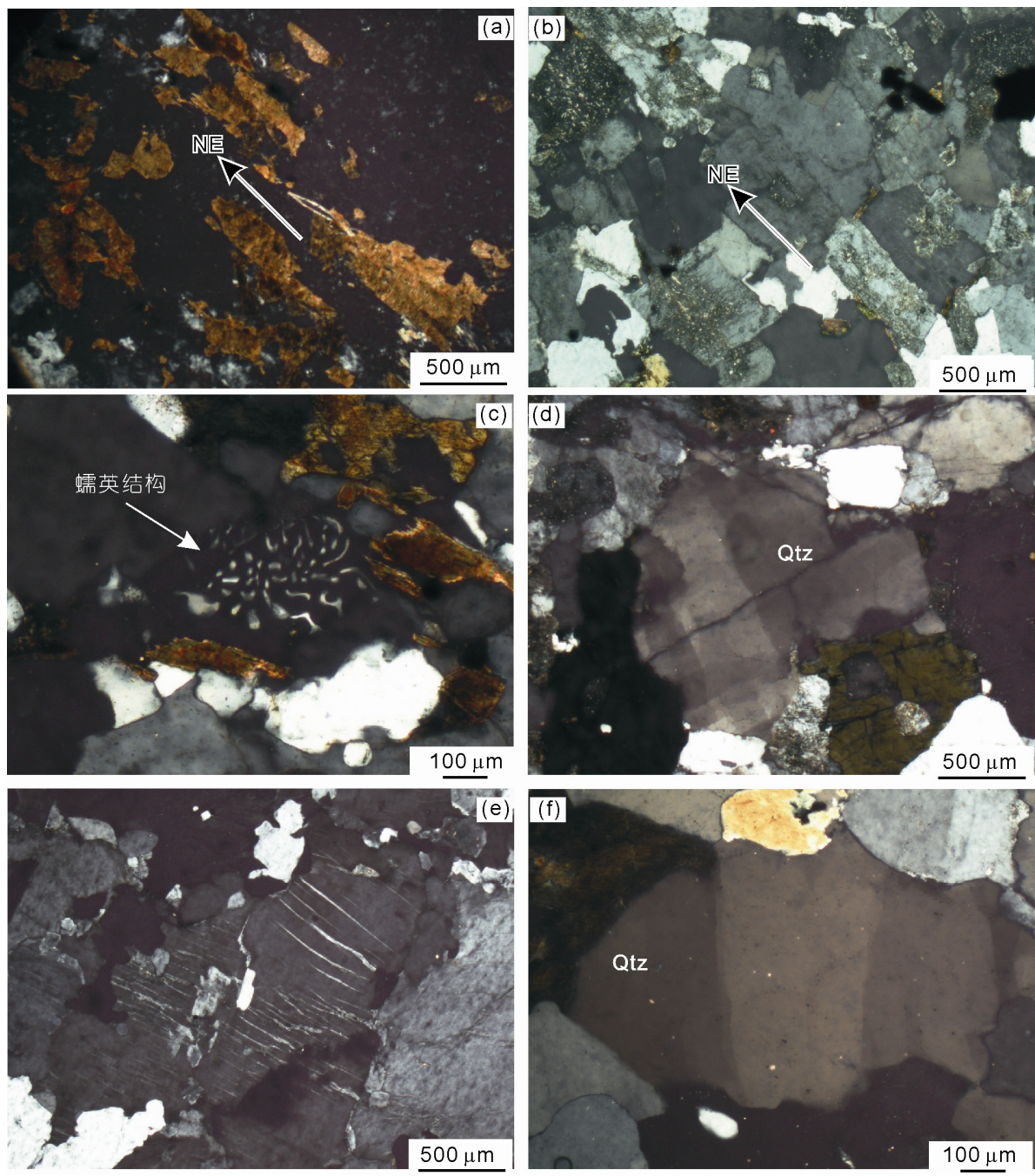

图 5 石鼓尖岩体显微变形照片

(a) 黑云母晶体沿 NE-SW 向定向排列, 反映结晶成岩时 NW-SE 向挤压作用; (b) 钾长石晶体沿 NE-SW 向定向排列, 结晶过程中受到 NW-SE 向挤压; (c) 应力蠕英结构, 反映钾长石在高温亚固态情况下受应力作用发生变形; (d) 石英棋盘状结构及柱状亚颗粒, 反映岩石在高温亚固 态情况下受应力作用发生变形; (e) 钾长石中火焰状出溶条纹及长石裂隙被小颗粒晶体充填; (f) 石英条带状消光及柱状亚颗粒, 应力导致晶 格位错运动形成规则的位错壁, 由位错壁分割成不同的消光区

4.87\% 8.35\%之间，极密值较大，反应岩体变形较强. 点极密主要分布在边缘及边缘与中心的中间位置. $Z$ 轴两边两个极密的夹角(开角)已标注在每个组构图 顶上，开角大小在 $66^{\circ} \sim 84^{\circ}$ 之间. Kruhl ${ }^{[42]}$ 认为在绿片 岩相和角闪岩相条件下，石英 $\mathrm{C}$ 轴组构的开角随着 变形温度的升高呈线性增大(图 7), 石英变形以底面 滑移 (<a>slip) 为主, 开角与变形温度关系图解所确定 的值误差在 $\pm 50^{\circ} \mathrm{C}$. 通过 $\mathrm{Kruhl}^{[42]}$ 建立的石英 $\mathrm{C}$ 组构 开角与变形温度关系图解(图 7), 石鼓尖岩体的变形 温度主要在 550 650 ${ }^{\circ} \mathrm{C}$ 之间, 变形温度较高.

\section{4 石鼓尖岩体锆石 U-Pb 定年}

在岩体东南部 DT04 $\left(31^{\circ} 00.856^{\prime} \mathrm{N}, 115^{\circ} 56.502^{\prime} \mathrm{E}\right.$; 见图 1)采集测年样品, 采样点位置变形较弱, 无后期 岩脉穿插, 岩石样品为典型的石英二长岩. 对所采集 样品进行机械粉碎, 经摇床、淘洗、电磁分选及重液 分选等步骤分离出锆石，在双目镜下挑选测年锆石. 锆石多呈棕色, 透明度较差. 大小不均匀, 多呈长柱 状, 晶面平直, 长约为 $100 \sim 200 \mu \mathrm{m}$, 长宽比约为 $1.5: 1$ 至 3:1, CL 图像(图 8(a))显示大部分锆石具有韵 


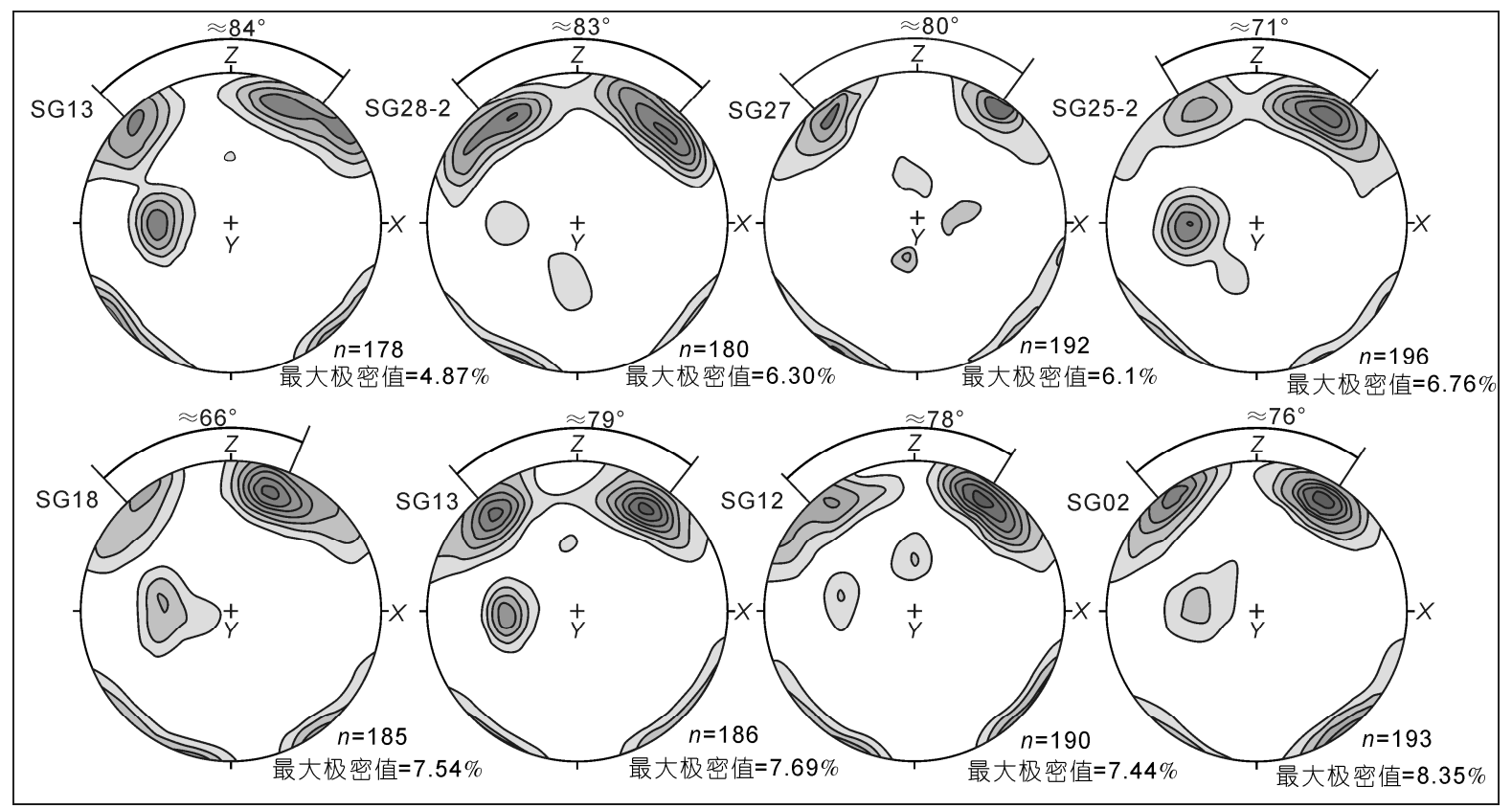

图 6 石鼓尖岩体石英 $\mathbf{C}$ 轴组构(下半球投影)

$Z$ 轴两边两个极密的夹角(开角)标在每个组构图的顶上

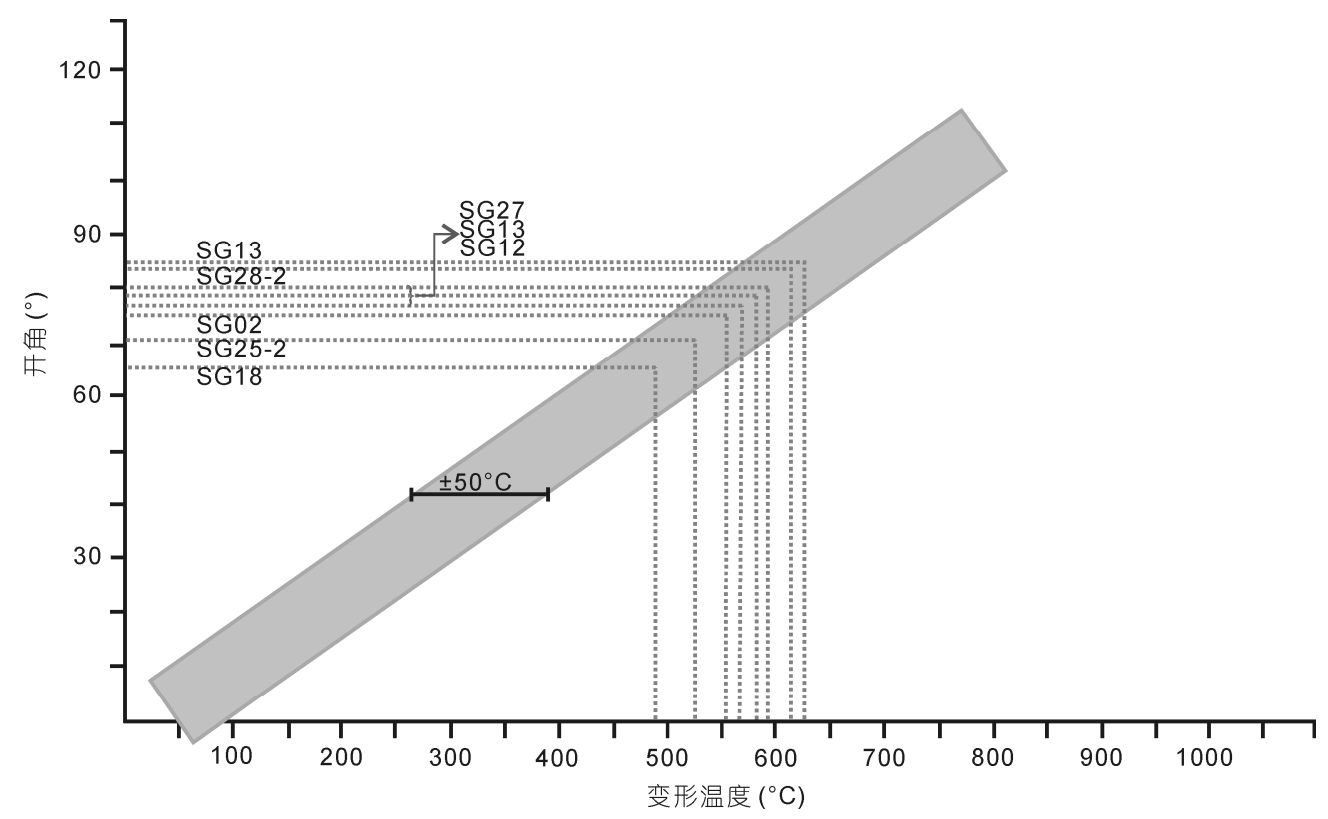

图 7 石英 $\mathbf{C}$ 轴组构开角与变形温度关系图解 修改自文献[42]

律环带结构, 但环带不清楚, 具有岩浆锆石一般的特 点, 为典型的岩浆锆石.

对样品 DT04 中 18 颗锆石进行 19 个年龄点测试,
测试结果列于表 2. 所测数据点的 $\mathrm{Th} / \mathrm{U}$ 比值均大于 0.5 , 在 $0.73 \sim 1.89$, 具有典型岩浆锆石特征. ${ }^{206} \mathrm{~Pb} /{ }^{238} \mathrm{U}$ 年龄介于 $(113.5 \pm 2.9) \sim(148.8 \pm 4.2) \mathrm{Ma}$ 之间, 加权平 

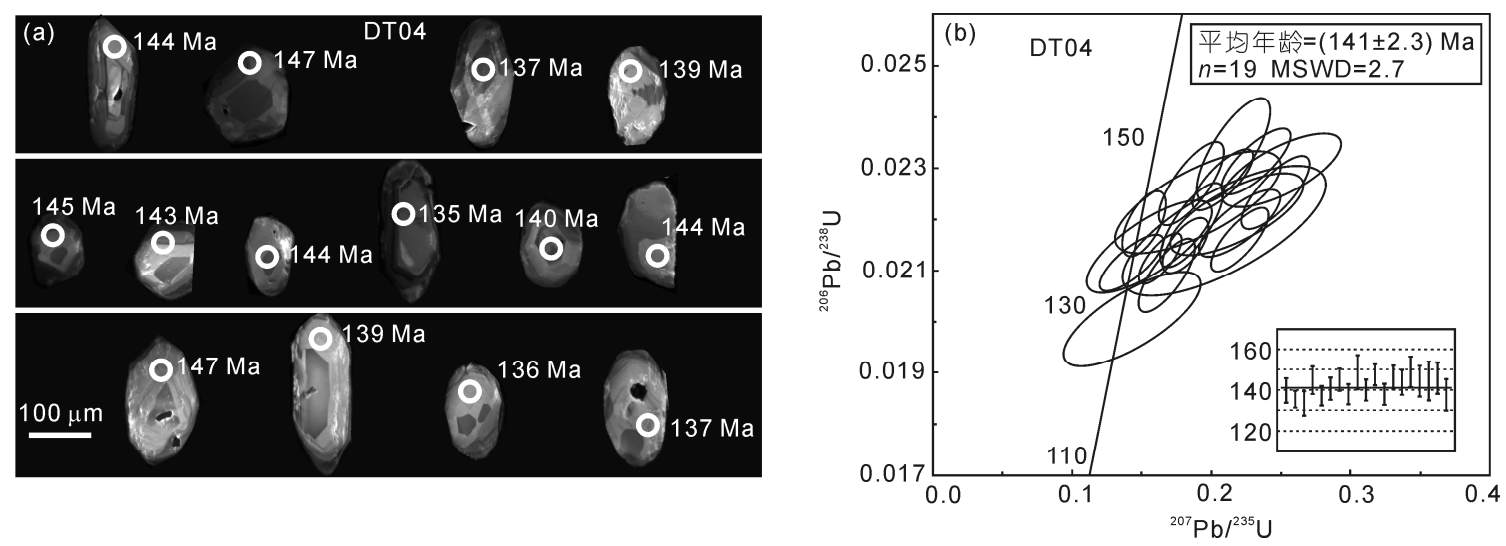

图 8 石鼓尖岩体典型锆石 $\mathrm{CL}$ 图像及 ${ }^{206} \mathrm{~Pb} /{ }^{238} \mathrm{U}$ 年龄 $(\mathrm{a})$ 和锆石 $\mathrm{U}-\mathrm{Pb}$ 年龄谐和图(b)

表 2 石鼓尖岩体样品 DT04 中锆石 U-Pb 定年结果

\begin{tabular}{cccccccccc}
\hline 点号 & $\begin{array}{c}\mathrm{Pb} \\
(\mathrm{ppm})\end{array}$ & $\begin{array}{c}\mathrm{U} \\
(\mathrm{ppm})\end{array}$ & $\begin{array}{c}\mathrm{Th} \\
(\mathrm{ppm})\end{array}$ & $\mathrm{Th} / \mathrm{U}$ & $\begin{array}{c}{ }^{207} \mathrm{~Pb} /{ }^{235} \mathrm{U} \\
(\%)\end{array}$ & $\begin{array}{c}{ }^{206} \mathrm{~Pb} /{ }^{238} \mathrm{U} \\
(\%)\end{array}$ & $\begin{array}{c}{ }^{207} \mathrm{~Pb} /{ }^{206} \mathrm{~Pb} \\
(\%)\end{array}$ & $\begin{array}{c}{ }^{206} \mathrm{~Pb} /{ }^{238} \mathrm{U} \text { 年龄 } \\
(\mathrm{Ma})\end{array}$ & $\begin{array}{c}{ }^{207} \mathrm{~Pb} /{ }^{235} \mathrm{U} \text { 年龄 } \\
(\mathrm{Ma})\end{array}$ \\
\hline 1 & 5.41 & 213 & 155 & 0.73 & $0.1510 \pm 1.1$ & $0.0219 \pm 0.0$ & $0.0524 \pm 0.4$ & $139.6 \pm 3.0$ & $142.8 \pm 9.6$ \\
2 & 4.24 & 134 & 253 & 1.89 & $0.1638 \pm 1.1$ & $0.0212 \pm 0.0$ & $0.0572 \pm 0.4$ & $135.4 \pm 2.0$ & $154.0 \pm 9.2$ \\
3 & 3.03 & 104 & 153 & 1.47 & $0.1682 \pm 1.3$ & $0.0209 \pm 0.0$ & $0.0634 \pm 0.5$ & $133.5 \pm 2.9$ & $157.9 \pm 11.3$ \\
4 & 3.48 & 117 & 145 & 1.24 & $0.1853 \pm 1.5$ & $0.0227 \pm 0.1$ & $0.0637 \pm 0.6$ & $144.7 \pm 3.4$ & $172.6 \pm 13.1$ \\
5 & 4.59 & 151 & 209 & 1.39 & $0.1806 \pm 1.2$ & $0.0215 \pm 0.0$ & $0.0626 \pm 0.4$ & $136.9 \pm 2.3$ & $168.5 \pm 10.0$ \\
6 & 3.86 & 131 & 183 & 1.39 & $0.1894 \pm 1.2$ & $0.0220 \pm 0.0$ & $0.0652 \pm 0.5$ & $140.4 \pm 2.8$ & $176.1 \pm 10.2$ \\
7 & 3.50 & 111 & 154 & 1.39 & $0.2069 \pm 1.4$ & $0.0228 \pm 0.0$ & $0.0664 \pm 0.5$ & $145.3 \pm 2.6$ & $191.0 \pm 11.5$ \\
8 & 4.85 & 171 & 1463 & 0.95 & $0.1989 \pm 1.4$ & $0.0216 \pm 0.0$ & $0.0692 \pm 0.5$ & $137.9 \pm 2.9$ & $184.1 \pm 11.8$ \\
9 & 3.77 & 115 & 158 & 1.37 & $0.2155 \pm 1.8$ & $0.0234 \pm 0.1$ & $0.0691 \pm 0.6$ & $148.8 \pm 4.2$ & $198.2 \pm 15.1$ \\
10 & 3.10 & 105 & 127 & 1.21 & $0.2324 \pm 1.6$ & $0.0231 \pm 0.0$ & $0.0756 \pm 0.5$ & $147.2 \pm 2.8$ & $212.2 \pm 13.6$ \\
11 & 3.07 & 95 & 164 & 1.72 & $0.2213 \pm 1.8$ & $0.0219 \pm 0.0$ & $0.0774 \pm 0.7$ & $139.8 \pm 2.6$ & $203.0 \pm 15.2$ \\
12 & 3.76 & 121 & 166 & 1.37 & $0.2218 \pm 1.4$ & $0.0216 \pm 0.0$ & $0.0793 \pm 0.6$ & $138.0 \pm 2.5$ & $203.4 \pm 11.9$ \\
13 & 3.02 & 98 & 122 & 1.24 & $0.2491 \pm 2.7$ & $0.0229 \pm 0.0$ & $0.0821 \pm 0.9$ & $146.2 \pm 2.9$ & $225.8 \pm 22.2$ \\
14 & 2.97 & 97 & 129 & 1.34 & $0.2452 \pm 1.6$ & $0.0225 \pm 0.0$ & $0.0845 \pm 0.6$ & $143.7 \pm 3.1$ & $222.7 \pm 13.0$ \\
15 & 3.36 & 93 & 157 & 1.69 & $0.3002 \pm 2.5$ & $0.0233 \pm 0.1$ & $0.0955 \pm 0.7$ & $148.6 \pm 3.8$ & $266.6 \pm 19.6$ \\
16 & 4.67 & 130 & 198 & 1.52 & $0.2926 \pm 2.5$ & $0.0227 \pm 0.1$ & $0.1002 \pm 0.9$ & $144.4 \pm 3.7$ & $260.6 \pm 20.0$ \\
17 & 2.76 & 85 & 121 & 1.42 & $0.3110 \pm 3.6$ & $0.0227 \pm 0.1$ & $0.1046 \pm 1.2$ & $144.5 \pm 4.7$ & $274.9 \pm 27.8$ \\
18 & 2.98 & 86 & 117 & 1.37 & $0.3377 \pm 2.1$ & $0.0231 \pm 0.0$ & $0.1085 \pm 0.7$ & $147.2 \pm 3.1$ & $295.5 \pm 15.8$ \\
19 & 5.26 & 152 & 242 & 1.59 & $0.3181 \pm 2.5$ & $0.0216 \pm 0.1$ & $0.1084 \pm 0.8$ & $137.7 \pm 3.9$ & $280.4 \pm 19.0$ \\
\hline
\end{tabular}

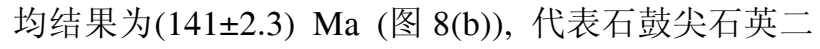
长岩侵位结晶年龄.

对于石鼓尖岩体, Xu 等 ${ }^{[15]}$ 在点 DB03C-35 (图 2) 采集岩石进行锆石 SHRIMP U-Pb 定年, 给出结晶年 龄为 $(131.8 \pm 3.9) \mathrm{Ma}$ ，但岩体年龄值变化范围较大 (142.4 \pm 6.2$) \sim(121.5 \pm 7.8) \mathrm{Ma}$, 石鼓尖石英二长岩的实 际结晶年龄应该大于 $(131.8 \pm 3.9) \mathrm{Ma}$. 造成这个结果 是因为靠近采样点 DB03C-35 附近有后期侵入体, 可 能采集为后期侵入体. 因此, 本文所测石鼓尖岩体侵 位结晶年龄 $(141 \pm 2.3) \mathrm{Ma}$ 应该是可靠的.

\section{5 讨论}

\section{1 石鼓尖岩体的同构造花岗岩特点}

石鼓尖岩体构造分析显示，该岩体具有同构造 花岗岩特点. 其证据如下：(1) 显微构造分析显示, 石鼓尖岩体中自形-半自形钾长石和黑云母晶体定向 排列, 晶体长轴规律地沿 NE-SW 展布, 反映岩体在 冷凝成岩过程中受到 NW-SE 向挤压; 岩体钾长石蠕 英结构和石英棋盘状结构发育，反映岩体在高温接 近固结成岩的情况下发生挤压变形 ${ }^{[5,6,39 \sim 42]}$; 钾长石 
晶体发育 NE-SW 向展布的应力纹, 反映 NE-SW 向剪 切作用; 岩体中石英条带状消光及柱状亚颗粒普遍 发育, 石英条带状消光及柱状亚颗粒的出现与应力 有关, 应力导致晶格位错运动形成规则的位错壁, 由 位错壁分割成不同的消光区; 显微结构分析都表明 岩体在高温接近固结成岩情况下发生挤压变形, 岩 体在侵位冷凝成岩过程中受到挤压应力作用. (2) 石 英 $\mathrm{C}$ 轴组构分析显示岩体变形温度在 $550 \sim 650^{\circ} \mathrm{C}$ 之间, 岩体在高温下发生同构造挤压变形. (3) 石鼓尖岩体 的磁化率各向异性度值 $P$ 变化较大, 从 $1.065 ~ 1.565$ 之间, 并且在 $67 \%$ 采样点大于 1.2 , 因此, 石鼓尖岩体 不具有流动磁组构特征而为变形磁组构 ${ }^{[37]}$. 对于花 岗岩类侵入体, 其磁组构比较稳定, 岩体发生的脆性 破裂不会明显改变其磁组构特征 ${ }^{[32]}$. 因此, 石鼓尖侵 入体的变形磁组构反映岩体侵位后期在高温接近固 态条件下发生韧性变形, 岩体磁化率椭球体形态因 子 $T$ 大于 0 及磁组构 $F-L$ 图解 $K$ 值小于 1 显示其在 冷凝成岩过程中受到挤压应力作用. (4) 岩体磁面理 走向总体为 $\mathrm{NE}$ 向, 倾向 $\mathrm{SE}$, 岩体在侵位冷凝成岩过 程中受 NW-SE 向挤压. 岩体的磁面理和片麻理与围 岩的片麻理走向及倾向相一致. 石鼓尖岩体被 NE 走 向右行脆-韧性剪切带围限, 剪切带早期具有逆冲特 征, 后期转换为右行走滑型脆-韧性剪切带, 剪切带 与岩体变形呈过渡关系, 与岩体磁面理和片麻理走 向协调, 岩体侵位与 NE 向走滑㓞性剪切带形成及运 动处同一构造应力场. 因此, 石鼓尖岩体是在侵位冷 凝成岩过程中发生挤压变形的同构造侵入体.

\section{2 石鼓尖岩体侵位}

石鼓尖岩体被 NE 走向脆-韧性剪切带围限, 剪 切带早期具有逆冲特征, 后期转换为右行走滑型脆韧性剪切带; 岩体显微构造和变形磁组构特征反映 岩体在侵位冷凝成岩过程中受到 NW-SE 向挤压作用, 发生 NW-SE 向构造缩短, NE-SW 向剪切. NE 向剪切 带的形成及运动与岩体侵位同期, 处于同一构造应 力场.

朱光等 ${ }^{[20,21]}$ 和 Wang ${ }^{[43]}$ 研究表明郯庐断裂带在晚 侏罗世初或中、晚侏罗世之交发生了一次左行平移, 这次左行平移事件代表了中国东部滨太平洋构造域 开始的时间. 中国东部在由古特提斯构造域转换为 滨太平洋构造域之后, 滨太平洋构造域内由于太平 洋区伊佐奈岐板块俯冲方向和俯冲角度的变化 ${ }^{[44,45]}$,
又发生了由压扭性动力体制向伸展性动力体制的转 换 ${ }^{[20]}$. 根据以上对石鼓尖岩体和 NE 向走滑脆-韧性 剪切带的研究, 石鼓尖岩体的侵位变形和 NE 向右行 走滑脆-韧性剪切带的形成及运动形成于滨太平洋构 造域压扭性动力体制下.

侵入体、韧性剪切带和压缩转化区具有密切的联 系 ${ }^{[46 ~ 48]}$. 已有研究表明, 花岗岩类侵入体的岩浆能 够通过较窄的构造薄弱带或者剪切带从源区到达中 地壳 ${ }^{[49,50]}$. Vigneresse 和 Tikoff ${ }^{[49]}$ 认为应力的水平分 量使熔融体水平迁入到构造薄弱带或者剪切带内, 而韧性剪切带作为垂直或近垂直的通道使岩浆进入 到更浅构造部位, 在这过程中应力与应变起到动力 作用. 石鼓尖岩体岩浆形成于加厚的下地壳, 属于壳 幔混源 ${ }^{[1,52]}$. 王强等 ${ }^{[53]}$ 通过对岩体岩浆演化的 $P-T$ 轨 迹研究, 认为石鼓尖侵入体的岩浆上升能力较强, 上 升的最小距离为 $25 \mathrm{~km}$, 为异地侵入体. 因此, 可以 认为石鼓尖岩体是在 SE-NW 挤压应力作用下, 熔融 体进入到构造薄弱带或者韧性剪切带内, 以构造薄 弱带为上升通道上升到地壳浅层次, 这个过程与 $\mathrm{NE}$ 向韧性剪切带活动同期(图 9).

\section{3 大别造山带构造体制转换的时限}

关于中生代大别造山带由挤压动力体制向伸展 动力体制转化的时间, 前人已有一定程度的研究. Hacker 等 ${ }^{[19]}$ 认为大别造山带在大约 140 120 Ma 之间 发生 NW-SE 向伸展; Wang 等 ${ }^{[18]}$ 认为大别造山带在 $143 \sim 110 \mathrm{Ma}$ 之间发生了上盘向 NW 或 WNW 向的剪 切, 这代表大别造山带此时已开始伸展活动; 朱光 等 ${ }^{[20,21]}$ 对郯庐断裂带内与伸展活动有关的岩浆岩进 行 LA-ICPMS 定年, 表明断裂带内与伸展活动有关 的、最早的岩浆活动发生在 $136 \mathrm{Ma}$; 朱光等 ${ }^{[17]}$ 又对淡 庐断裂带所控制断陷盆地内地层充填序列进行研究, 指示断裂带的伸展活动开始于早白严世初(约 $145 \mathrm{Ma}$ ). 这所有研究都表明大别造山带伸展活动开始的时间在 早白严世初, 但具体开始时间没有定论. 石鼓尖岩体 的变形构造研究和磁组构特征显示, 岩体在侵位冷 凝成岩过程中受到 NW-SE 向的挤压, 岩体侵位时大 别造山带仍然处于挤压环境, 岩体锆石 U-Pb 定年为 (141 \pm 2.3$)$ Ma. 结合已有研究, 大别造山带伸展活动开

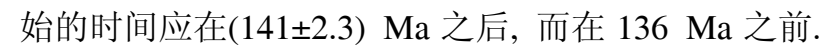
大别造山带在短短的几个百万年时间内就完成了由挤 压动力学体制向伸展动力学体制的转换. 
包括大别造山带在内的中国东部古生代和中生 代的构造演化主要受近东西向特提斯构造域和 NE-NNE 向滨太平洋构造域控制 ${ }^{[54]}$. 大别造山带在 三叠纪晚期最后完成碰撞、拼合 ${ }^{[55 ~ 59]}$, 造山作用受控 于古特提斯构造域, 在 SW-NE 或者近 N-S 向构造挤 压应力作用下扬子板块与华北板块碰撞、俯冲(图 $10(\mathrm{a}))^{[59]}$. 早、中侏罗世, 下扬子地区主要应力场与晚
三叠世之前区域应力场相比有较小角度的逆时针旋 转, 应力场分析显示为总体 NNW-SSE 向或近 S-N 向 挤压，这说明早、中侏罗世区域应力场与晚三叠世有 明显的继承性, 早、中侏罗世下扬子地区的陆内挤压 仍受古特提斯构造体系控制(图 10(b) $)^{[60]}$. 早白严世 早期, 应力场分析显示出现 NW-SE 向的挤压构造(图 10(b)), 挤压应力场与侏罗纪相比有逆时针变化, 中

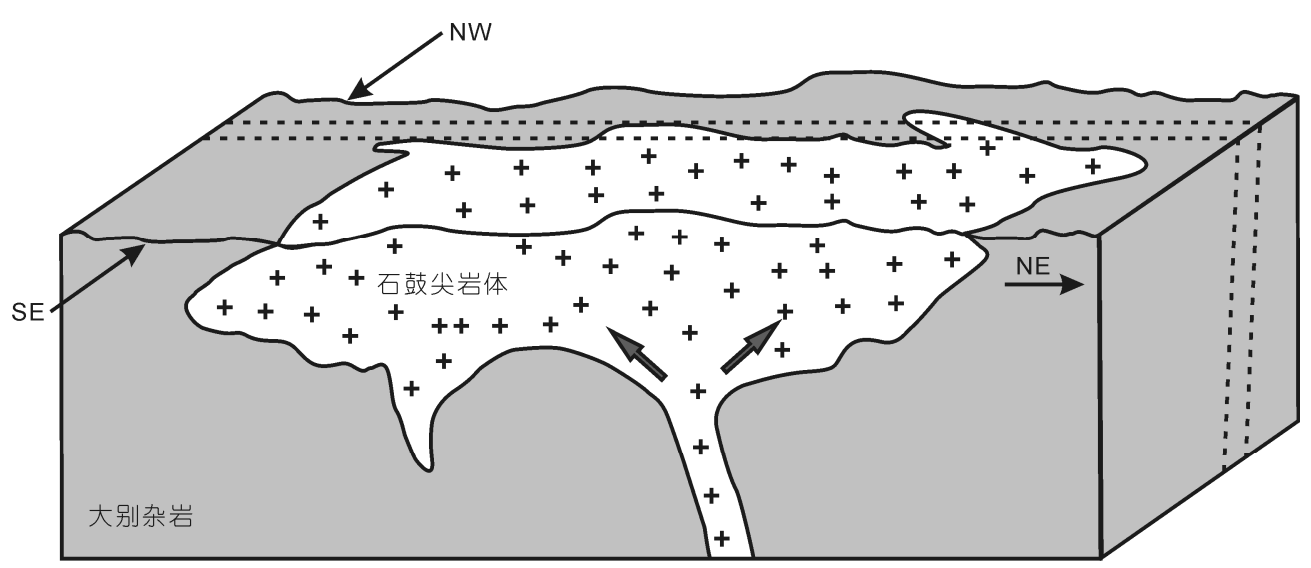

图 9 石鼓尖岩体侵位模式图
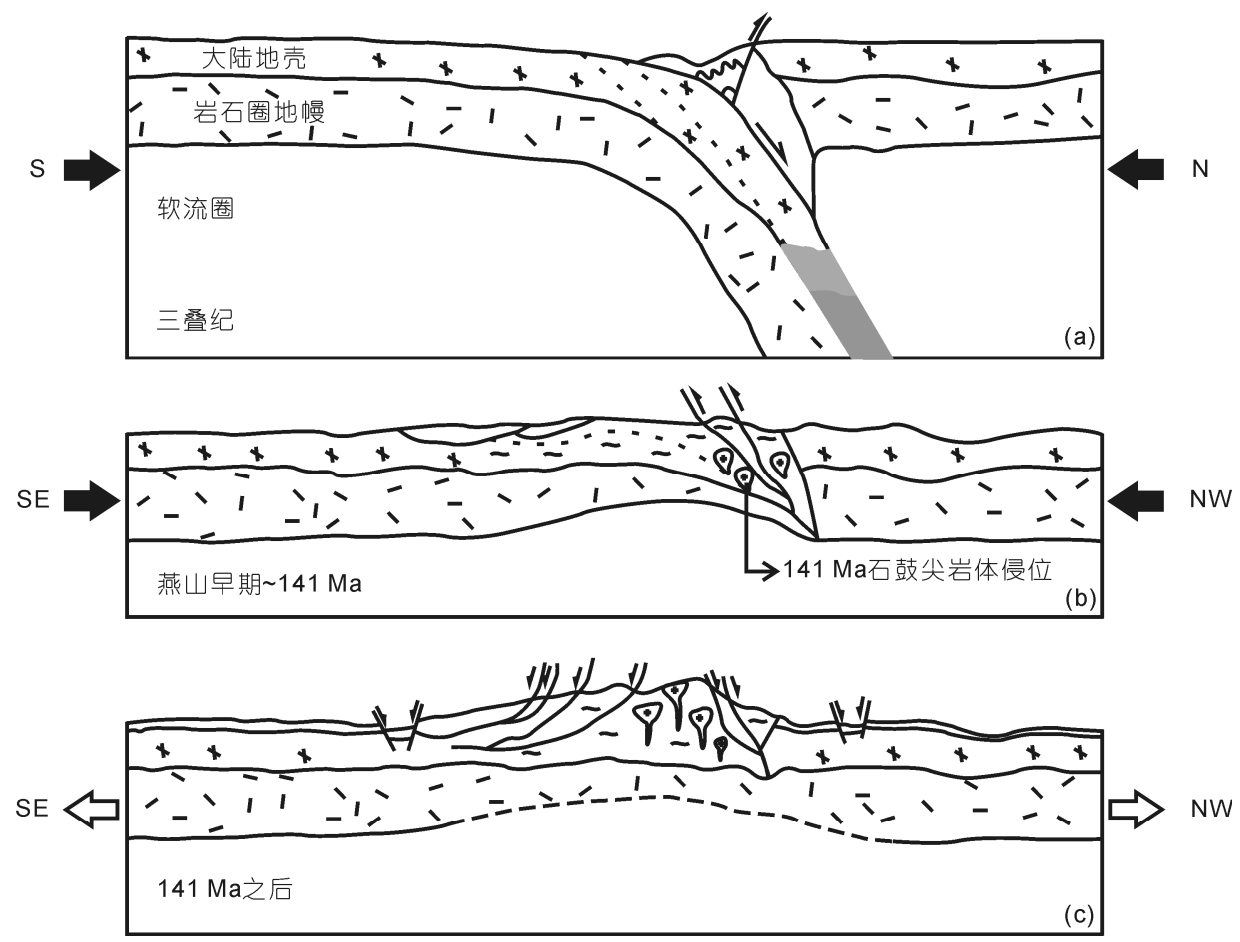

图 10 大别造山带不同时期应力状态及构造体制示意图

(a) 三叠纪时期造山带在 N-S 向挤压应力作用下碰撞俯冲; (b) 燕山早期 141 Ma 造山带挤压应力逐渐由 N-S 向逆时针旋转为 NW-SE 向, 伴 随构造演化及部分岩浆侵入; (c) 141 Ma 之后大别造山带由 NW-SE 向挤压转化为 NW-SE 向伸展, 大量岩浆侵入 
国东部转为受控于滨太平洋构造域 ${ }^{[60]}$. 石鼓尖岩体 在 NW-SE 向挤压应力作用下侵位冷凝成岩, 岩体锆 石 $\mathrm{U}-\mathrm{Pb}$ 年龄为 $(141 \pm 2.3) \mathrm{Ma}$. 因此, 在 $(141 \pm 2.3) \mathrm{Ma}$ 石鼓尖岩体侵位冷凝成岩时大别造山带的构造演化
已经受控于滨太平洋构造域, 古特提斯构造域向西 太平洋构造域的转换应在 $141 \mathrm{Ma}$ 之前. 在 $141 \mathrm{Ma}$ 之 后大别造山带完全受控于滨太平洋构造域(图 10(c)), 造山带处于 NW-SE 向伸展环境. 助, 评审专家对本文提出宝贵意见和建设性建议, 在此一并感谢.

\section{参考文献}

1 Brown M, Solar G S. Granite ascent and emplacement during contractional deformation in convergent orogens. J Struct Geol, 1998, 20: 1365-1393

2 Brown M, Solar G S. Shear-zone systems and melts: Feedback relations and self-organization in orogenic belts. J Struct Geol, 1998, 20: 211-227

3 Pressley R A, Brown M. The Phillips pluton, Maine, USA: Evidence of heterogeneous crustal sources and implications for granite ascent and emplacement mechanisms in convergent orogens. Lithos, 1999, 46: 335-366

4 Simpson C. Deformation of granitic rocks across the brittle-ductile transition. J Struct Geol, 1985, 7: 503-511

5 Paterson S R, Vernon R H, Tobisch O T. A review of criteria for the identification of magmatic and tectonic foliations in granitoids. J Struct Geol, 1989, 11: 349-363

6 Mamtani M A, Greiling R O. Granite emplacement and its relation with regional deformation in the Aravalli Mountain Belt (India) - Inferences from magnetic fabric. J Struct Geol, 2005, 27: 2008-2029

7 Njanko T, Nédélec A, Kwékam M, et al. Emplacement and deformation of the Fomopéa pluton: Implication for the Pan-African history of Western Cameroon. J Struct Geol, 2010, 32: 306-320

8 Xue F, Rowley D B, Tucker R D, et al. U-Pb zircon ages of granitoid rocks in the North Dabie Complex, Eastern Dabie Shan, China. J Geol, 1997, 105: 744-753

9 Hacker B R, Ratschbacher L, Webb L, et al. U/Pb zircon ages constrain the architecture of the ultrahigh-pressure Qinling-Dabie Orogen, China. Earth Planet Sci Lett, 1998, 161: 215-230

10 Bryant D L, Ayers J C, Gao S, et al. Geochemical, age, and isotopic constraints on the location of the Sino-Korean/Yangtze Suture and evolution of the Northern Dabie Complex, east central China. Geol Am Bull, 2004, 116: 698-717

11 Xie Z, Zheng Y F, Zhao Z F, et al. Mineral isotope evidence for the contemporaneous process of Mesozoic granite emplacement and gneiss metamorphism in the Dabie orogen. Chem Geol, 2006, 231: 214-235

12 Wang Q, Wyman D A, Xu J, et al. Early Cretaceous adakitic granites in the Northern Dabie Complex, central China: Implications for partial melting and delamination of thickened lower crust. Geochim Cosmochim Acta, 2007, 71: 2609-2636

$13 \mathrm{Xu} \mathrm{H} \mathrm{J,} \mathrm{Ma} \mathrm{C} \mathrm{Q,} \mathrm{Ye} \mathrm{K.} \mathrm{Early} \mathrm{cretaceous} \mathrm{granitoids} \mathrm{and} \mathrm{their} \mathrm{implications} \mathrm{for} \mathrm{the} \mathrm{collapse} \mathrm{of} \mathrm{the} \mathrm{Dabie} \mathrm{orogen,} \mathrm{eastern} \mathrm{China:} \mathrm{SHRIMP}$ zircon U-Pb dating and geochemistry. Chem Geol, 2007, 240: 238-259

14 Xie Z, Chen J F, Cui Y R. Episodic growth of zircon in UHP orthogneisses from the North Dabie Terrane of east-central China: Implications for crustal architecture of a collisional orogen. J Metamorph Geol, 2010, 240: 1314-1525

15 续海金. 大别造山带核部晚中生代岩浆侵位序列与构造体制转换. 博士学位论文. 武汉: 中国地质大学, 2005

16 续海金, 叶凯, 马昌前. 北大别早白严纪花岗岩类的 Sm-Nd 和锆石 $\mathrm{Hf}$ 同位素及其构造意义. 岩石学报, 2008, 24: 87-103

17 朱光, 朴学峰, 张力, 等. 合肥盆地伸展方向的演变及其动力学机制. 地质论评. 2011: 153-166

18 Wang Y S, Xiang B W, Zhu G, et al. Structural and geochronological evidence for Early Cretaceous orogen-parallel extension of the ductile lithosphere in the northern Dabie orogenic belt, East China. J Struct Geol, 2011, 33: 362-380

19 Hacker B R, Ratschbacher L, Webb L, et al. Exhumation of ultrahigh-pressure continental crust in east central China: Late Triassic-Early Jurassic tectonic unroffing. J Geophys Res, 2000, 105: 13339-13364

20 朱光, 张力, 谢成龙, 等. 欵庐断裂带构造演化的同位素年代学制约. 地质科学, 2009, 44: 1327-1342

21 Zhu G, Niu M L, Xie C L, et al. Sinistral to normal faulting along the Tan-Lu Fault Zone: Evidence for geodynamic switching of the east China continental margin. J Struct Geol, 2010, 118: 277-293

22 Okay A I, Sengör A M C, Satir M. Tectonics of an ultrahigh-pressure metamorphic terrane: The Dabie Shan/Tongbai Shan Orogen, China. 
Tectonics, 1993, 12: 1320-1334

23 Maruyama S, Liou J G, Zhang R Y. Tectonic evolution of the ultrahigh-pressure (UHP) and high-pressure (HP) metamorphic belts from central China. Island Arc, 1994, 3: 112-121

24 Zhai M G, Cong B L, Zhao Z Y, et al. Petrological-tectonic units in the coesite-bearing metamorphic terrain of the Dabie Mountains, central China and their geotectonic implications. J Southeast Asian Earth Sci, 1995, 11: 1-13

25 徐树桐, 刘贻灿, 江来利, 等. 大别造山带的构造几何学和运动学. 合肥: 中国科学技术大学出版社, 2002. 1-133

26 Zheng Y F, Zhou J B, Wu Y B, et al. Low-Grade Metamorphic Rocks in the Dabie-Sulu Orogenic Belt: A Passive-Margin Accretionary Wedge Deformed during Continent Subduction. Int Geol Rev. 2005, 47: 851-871

27 Zheng Y F, Fu B, Gong B, et al. Stable isotope geochemistry of ultrahigh pressure metamorphic rocks from the Dabie-Sulu orogen in China: Implications for geodynamics and fluid regime. Earth Sci Rev, 2003, 62: 105-161

28 Oliveira De D C, Neves S P, Trindade R I F, et al. Magnetic anisotropy of the Redenção granite, eastern Amazonian craton (Brazil): Implications for the emplacement of A-type plutons. Tectonophysics, 2010, 493: 27-41

29 Bolle O, Diot H, Liégeois J P, et al. The Farsund intrusion (SW Norway): A marker of late-Sveconorwegian (Grenvillian) tectonism emplaced along a newly defined major shear zone. J Struct Geol, 2010, 32: 1500-1518

30 López De Luchi M G, Rapalini A E, Tomezzolib R N. Magnetic fabric and microstructures of Late Paleozoic granitoids from the North Patagonian Massif: Evidence of a collision between Patagonia and Gondwana? Tectonophysics, 2010, 494: 118-137

31 杨坤光, 刘强, 刘育燕, 等. 大别山双河同构造花岗岩体显微构造与磁组构研究. 中国科学 D 辑: 地球科学, 2003, 33: 1050-1056

32 余钦范, 郑敏. 岩石磁组构分析及其在地学中的应用. 北京: 地质出版社, 1992.1

33 Jelinek V. Statistical processing of anisotropy of magnetic susceptibility measured on groups of specimens. Studia Geoph Geod, 1978, 142: $50-62$

34 Jelinek V. Characterization of the magnetic fabric of rocks. Tectonophysics, 1981, 79: 563-567

35 Rochette P. Magnetic susceptibility of the rock matrix related to magnetic fabric studies. J Struct Geol, 1987, 9: 1015-1020

36 Chadima M, Hrouda F, Melichar R. Magnetic fabric study of the SE Rhenohercynian Zone (Bohemian Massif): Implications for dynamics of the Paleozoic accretionary wedge. Tectonophysics, 2006, 418: 93-109

37 Hrouda F. Magnetic anisotropy of rocks and its application in geology and geophysics. Surv Geophys, 1982, 5: 37

38 Vernon R H. Review of microstructural evidence of magmatic and solid-state flow. Vis Geosci, 2000, 5: 1

39 Blenkinsop T. Deformation Microstructures and Mechanisms in Minerals and Rocks. Dordrecht: Kluwer Academic Publishers, 2000

40 Mccaffrey K J W, Miller C F, Karlstrom K E, et al. Synmagmatic deformation patterns in the Old Woman Mountains, SE California. J Struct Geol, 1999, 21: 335-349

41 Mainprice D, Bouchez J L, Blumenfeld P, et al. Dominant c slip in naturally deformed quartz: Implications for dramatic plastic softening at high temperature. Geology, 1986, 14: 819-822

42 Kruhl J H. Prism- and basal-plane parallel subgrain boundaries in quartz: A microstructural geothermobarometer. J Metamorph Geol. 1996, 14: 581-589

43 Wang Y. The onset of the Tan-Lu fault movement in eastern China: Constraints from zircon (SHRIMP) and ${ }^{40} \mathrm{Ar} /{ }^{39} \mathrm{Ar}$ dating. Terra Nova, 2006, 18: 423-431

44 Maruyama S, Isozaki Y, Kimura G, et al. Paleogeographic maps of the Japanese Islands: Plate tectonic synthesis from 750 Ma to the present. Island arc, 1997, 6: 121-142

45 朱光, 王道轩, 刘国生, 等. 郯庐断裂带的演化及其对西太平洋板块运动的响应. 地质科学, 2004: 36-49

46 D'Lemos R S, Brown M, Strachan R A. Granite magma generation, ascent and emplacement within a transpressional orogen. J Geol Soci, 1992, 149: 487-490

47 Ingram G M, Hutton D W H. The Great Tonalite Sill: Emplacement into a contractional shear zone and implications for Late Cretaceous to early Eocene tectonics in southeastern Alaska and British Columbia. GSA Bull, 1994, 106: 715-728

48 Greiling R O, Verma P K. Strike-slip and tectonics granitoid emplacement: An AMS fabric study from the Odenwald Crystalline Complex, SW Germany. Mineral Petrol, 2001, 72: 165

49 Vigneresse J L, Tikoff B. Strain partitioning during partial melting and crystallizing felsic magmas. Tectonophysics, 1999, 312: 117-132

50 Vigneresse J L, Clemens J D. Granitic magma ascent and emplacement: Neither diapirism nor neutral buoyancy. Geol Soc London Spec Publ, 2000, 174: 1-19

51 Zhao Z F, Zheng Y F, Wei C S, et al. Post-collisional granitoids from the Dabie orogen in China: Zircon U-Pb age, element and O isotope evidence for recycling of subducted continental crust. Lithos, 2007, 93: 248-272 
52 Zhao Z F, Zheng Y F, Wei C S, et al. Origin of postcollisional magmatic rocks in the Dabie orogen: Implications for crust-mantle interaction and crustal architecture. Lithos, 2011, 126: 99-114

53 王强, 邱家骧, 王人镜. 大别造山带核部典型燕山期花岗岩岩浆演化的 $P-T$ 轨迹. 矿物岩石, 1999, 19: 15-20

54 任纪舜, 牛宝贵, 和政军. 中国东部的构造格局和动力学演化. 北京: 原子能出版社, 1998. 1-12

55 李曙光, E Jagoutz, 萧益林, 等. 大别山-苏鲁地体超高压变质年代学— I. Sm-Nd 同位素体系. 中国科学 D 辑: 地球科学, 1996, 26: $249-257$

56 李曙光, 李惠民, 陈移之, 等. 大别山-苏鲁地体超高压变质年代学— II. 锆石 U-Pb 同位素体系. 中国科学 D 辑: 地球科学, 1997, 27: 200-206

57 索书田, 钟增球, 游振东, 等. 大别-苏鲁区残余超高压构造及其动力学意义. 地球科学, 2000, 25: 557-563

58 张国伟, 张本仁, 袁学诚, 等. 秦岭造山带与大陆动力学. 北京: 科学出版社, 2001: 855

59 李三忠, 张国伟, 董树文, 等. 大别山高压-超高压岩石折返与扬子北缘构造变形的关系. 岩石学报, 2010, 26: 3549-3562

60 侯明金, 朱光, Mercier Jacques. 郯庐断裂带(安徽段)及邻区的动力学分析与区域构造演化. 地质科学, 2007, 42: 362-381 